Available online at https://jurnal.stmikroyal.ac.id/index.php/jurdimas

\title{
MEMBANGUN KREATIFITAS PEMUDA MILENIAL MELALUI KONTEN VIDEO MULTIMEDIA KOMPUTER
}

\author{
Sahren $^{* 1}$, Irianto ${ }^{2}, \mathrm{Akmal}^{3}$ \\ ${ }^{1}$ Sistem Komputer, STMIK Royal Kisaran \\ ${ }^{2,3}$ Sistem Informasi, STMIK Royal Kisaran \\ email:*sahren@royal.com
}

\begin{abstract}
In the life of modern society today, humans always use technology in various activities such as information, industry, economics, and especially Multimedia. In the field of Multimedia, Editing must be able to keep abreast of these developments so that they do not lag behind in determining creativity. Video editors must use technology in learning such as the use of multimedia as a tool for transferring communications.
\end{abstract}

Keywords: Computer, Vidio, Multimedia

Abstrak: Dalam Kehidupan masyarakat modern dewasa ini, manusia selalu menggunakan teknologi dalam berbagai kegiatan seperti bidang informasi, industri, ekonomi, dan terutama bidang Multimedia. Dalam bidang Multimedia, para Editing harus sudah mampu mengikuti perkembangan tersebut agar mereka tidak ketinggalan dalam menentukan kreatifitas. Para Editing vidio harus menggunakan teknologi dalam pembelajaran seperti penggunaan multimedia sebagai alat untuk mentransfer komunikasi.

Kata kunci: Komputer, Vidio, Multimedia

\section{PENDAHULUAN}

Era globalisasi ini, perkembangan teknologi tidak dapat dibendung atau dihalangi dalam berbagai kehidupan kita sekarang ini. Semakin berkembang teknologi informasi, maka semakin menuntut perusahaan/oragnisani untuk mengikuti perkembangan teknologi informasi tersebut. Perkembangan teknologi ini telah mempengaruhi kehidupan kita sehari-hari.

Dalam Kehidupan masyarakat modern dewasa ini, manusia selalu menggunakan teknologi dalam berbagai kegiatan seperti bidang informasi, industri, ekonomi, dan terutama bidang Multimedia. Dalam bidang Multimedia, para Editing harus sudah mampu mengikuti perkembangan tersebut agar mereka tidak ketinggalan dalam menentukan kreatifitas. Para Editing vidio harus menggunakan teknologi dalam pembelajaran seperti penggunaan multimedia sebagai alat untuk mentransfer komunikasi. Selain itu, para peserta didik juga sudah sangat dekat perkembangan teknologi tersebut. Para peserta didik terkadang menggunakan multimedia sebagai sarana hiburan dan pembelajaran. Contohnya ketika mereka ingin membuat vlog mereka sendiri, mereka harus mampu menggunakan teknologi komputer. Para Editing vidio harus juga mampu menggunakan alat teknologi dalam mengupdate kreatifitasnya dalam menciptakan vidio. 
Available online at https://jurnal.stmikroyal.ac.id/index.php/jurdimas

Berdasarkan dasar pemikiran diatas maka kami membuat kegiatan Tri Dharma Perguruan Tinggi yaitu Pengabdian Kepada Masyarakat (PKM) yang bekerjasama dengan Lembaga Penelitian dan Pengabdian pada Masyarakat (LPPM) STMIK Royal Kisaran. Dalam kegiatan yang telah dilakukan maka kami memilih judul "Membangun Kreatifitas Pemuda Milenial Melalui Konten Video Multimedia Komputer" di MAS Cipta Simpang Dolok Lima Puluh Kabupaten Batubara Propinsi Sumatera Utara.

\section{PENGENALAN MULTIMEDIA}

Multimedia adalah penggunaan
komputer untuk menyajikan dan
menggabungkan teks, suara,
gambar,animasi, audio dan video dengan
alat bantu (tool) dan koneksi (link) sehingga
pengguna dapat melakukan navigasi,
berinteraksi, berkarya dan berkomunikasi.
Multimedia sering digunakan dalam dunia
informatika. Selain dari dunia informatika,
Multimedia juga diadopsi oleh dunia game,
dan juga untuk membuat website.

\section{Konsep dasar Multimedia}

Seperti yang telah dijelaskan sebelumnya (Pengertian Multimedia), multimedia adalah penggunaan komputer untuk menggabungkan informasi berupa teks, gambar, suara, animasi , atau bahkan video untuk ditampilkan untuk pengguna komputer . Ada dua jenis multimedia yaitu multimedia linear (tetap) dan multimedia interaktif (dapat dikendalikan). Pada multimedia interaktif, pengguna diberikan fasilitas untuk mengendalikan atau memainkan elemen-elemen multimedia yang tersedia.

\section{Tujuan Dasar Multimedia}

Pemanfaatan multimedia memiliki tujuan-tujuan dasar sebagai berikut,

- Meningkatkan efektifitas penyampaian informasi
- Mendorong partisipasi, eksploitasi dan interaksi pemakai

- Merancang panca indra, karena bersifat visual

- Memberikan kemudahan pemakaian.

\section{Elemen - elemen Multimedia}

\section{Teks}

Teks merupakan elemen multimedia yang paling sederhana dan mudah dimengerti. Selain itu teks lebih mudah diolah, disimpan dan tidak banyak memakai memori dalam sebuah media penyimpanan.

\section{Animasi}

Animasi adalah bentuk gambar yang bergerak. Dengan menampilkan banyak gambar secara cepat, bergantian dan terus-menurus sehingga menghasilkan efek sebuah gambar yang bergerak. Animasi lebih menarik dibanding bantuk gambar atau grafik biasa.

\section{Grafik}

Grafik sangat baik dalam mengilustrasikan suatu informasi. Grafik dapat berupa kurva, foto, hasil scanner maupun bentuk gambar lain baik dua dimensi atau tiga dimensi.

\section{Gambar}

Gambar merupakan suatu objek yang dapat ditampilkan dalam bentuk grafik (non teks) atau konsep yang berbentuk kode yang tidak berelasi dengan waktu.

\section{Suara}

dalam $\begin{gathered}\text { Pengunaan suara atau audio ke } \\ \text { aplikasi multimedia dapat }\end{gathered}$ memberikan informasi yang tidak mungkin diberikan oleh media informasi seperti gambar, grafik ataupun teks. Contohnya untuk menginformasikan bagaimana bunyi desiran angin tentu tidak bisa didepskripsikan oleh teks. 
Available online at https://jurnal.stmikroyal.ac.id/index.php/jurdimas

\section{Video}

Video seperti layaknya animasi namun video lebih cenderung hasil karya dari adegan dunia nyata yang direkam secara langsung. Dalam video terkandung juga elemen multimedia lainnya seperti gambar, suara dan tulisan.

\section{PEMBAHASAN}

Filmora atau lebih lengkapnya Wondershare Fimora Video Editor adalah sebuah aplikasi atau program yang dirancang untuk membuat proses pengeditan video dengan mudah dan senderhana tapi memili kualitas yang cukup powerful. Jika kita baru mengenal dunia video editing atau sudah lama bekercimpung di dunia video editing dan ingin proses pengeditannya lebih cepat dengan hasil yang maksimal, filmora merupakan salah satu pilihan yang tepat.

Wodershare Fimora Video Editor memiliki kelebihan antara lain:

1. Apikasi Ringan

2. Pengoperasiannya Sangat Mudah

3. Proses Editing Bisa Lebih Cepa

4. Banyak Efek Yang Tersedia

\section{Editing Video}

Wondershare Video Editor dilengkapi dengan 2 video editing modus yang berbeda modus mudah dan penuh fitur Mode untuk memenuhi kebutuhan editing video. Modus mudah memungkinkan pengguna dengan mudah membuat film sendiri dengan memberikan berbagai built-in template. Pastikan memilih rasio aspek yang tepat untuk tampilan video (4:3 atau 16:9) ketika memulai proyek video.

1. Setelah aplikasi wondershare filmora editing video terbuka langkah pertama adalah menentukan rasio untuk tampilan video. Pada gambar ini merupakan tampilan untuk memilih rasio tampilan video.

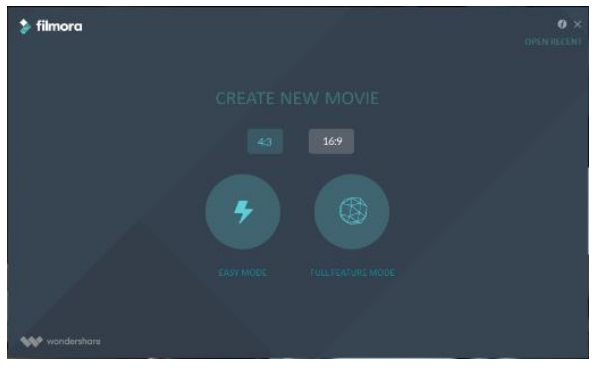

Gambar 1. Membuat Video Baru Pada Filmora

2. Pada tampilan filmora seperti tampak pada gambar di bawah ini terdapat beberapa komponen penting diantaranya. Bagian media dimana akan memuat bahan multimedia yang akan dipergunakan untuk membuat video.

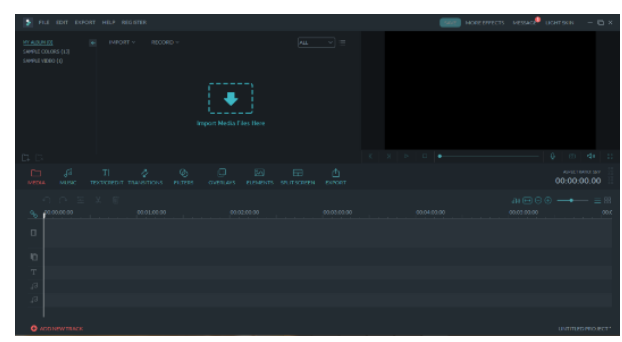

Gambar 2. Tampilan Filmora Full Fiture Mode

3. Hal pertama yang harus dilakukan untuk mengedit video adalah memiliki file atau bahan multimedia yang akan diedit, untuk melakukan editing kita perlu mengimport file-file tersebut kedalam filmora.

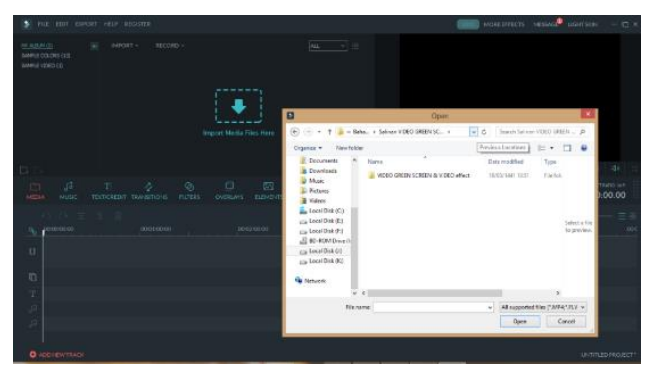

Gambar 3. Load Media Sebagai Bahan Editing Video 
Available online at https://jurnal.stmikroyal.ac.id/index.php/jurdimas

4. Pilih beberapa file yang kita butuhkan untuk membuat video seperti video yang akan diedit, gambar dan suara. Disini yang akan kita edit adalah video dengan latar belakang green screen. Tujuan editing video ini adalah kita akan mengganti background pada video green screen mennggunakan background yang kita inginkan.

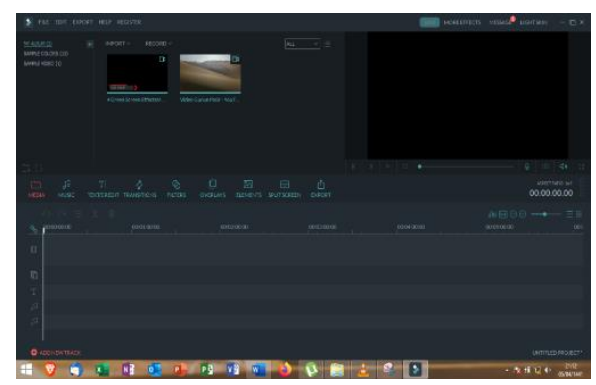

Gambar 4. Load Media Media Berhasil

5. Untuk mengganti background video green screen pertama kita harus mendrag file video yang kita miliki ke dalam timeline.

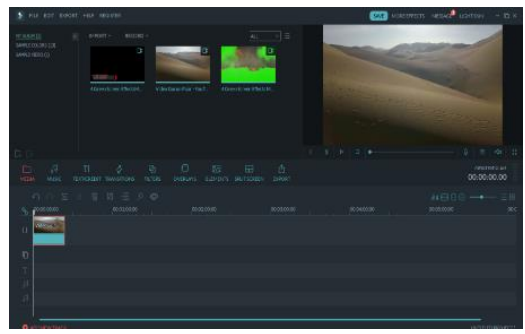

Gambar 5. Memasukkan File Video Ke Time Line

6. Setelah video pertama kita masukkan kedalam time line maka selajutnya kita kembali mendrag

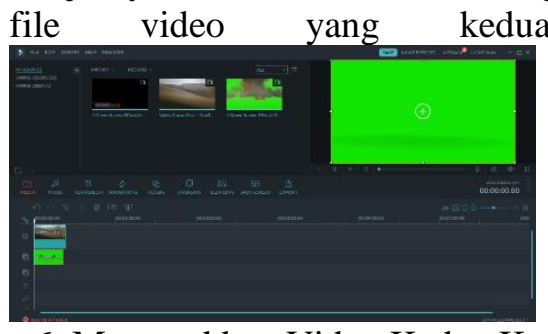

Gambar 6. Memasukkan Video Kedua Ke Timeline
7. Setelah kedua video yang merupakan bahan untuk melakukan editing, selanjutnya kita dapat memutar video tersebut dengan cara mengklik tombol play yang ada di filmora, hal ini dilakukan untuk melakukan pengecekan dan mensejajarkan durasi dan posisi dari kedua video tersebut.

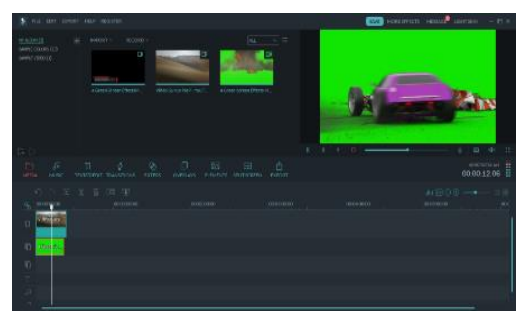

Gambar 7. Play Video Awal Sebelum Editing

8. Setelah dirasi pas untuk durasi dan posisi video yang akan kita editing langkah selanjutnya adalah menghilangkan background dari video green screen yang ada.

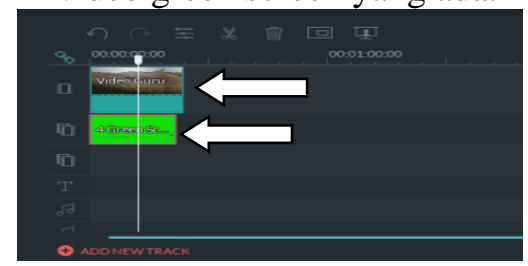

Gambar 8. Masuk Menu Green Screen

9. Setelah menu green screen di klik seperti pada gambar 9 .

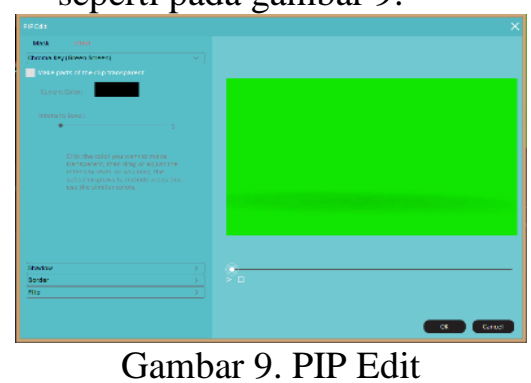

10. Setelah berada pada menu edit green screen seperti gap. Kemudian pada chek box kita harus mencentak atau cheklist pada Make Part of The Clip Transparant. 
Available online at https://jurnal.stmikroyal.ac.id/index.php/jurdimas

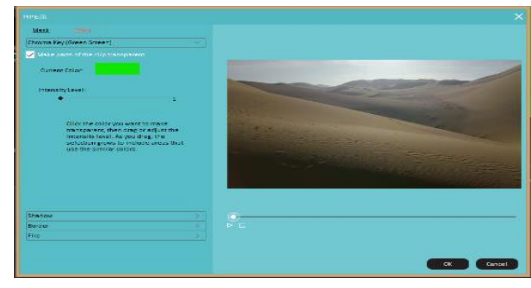

Gambar 10 Edit Green Screen

11. Setelah selesai kita hilangkan background hijaunya.

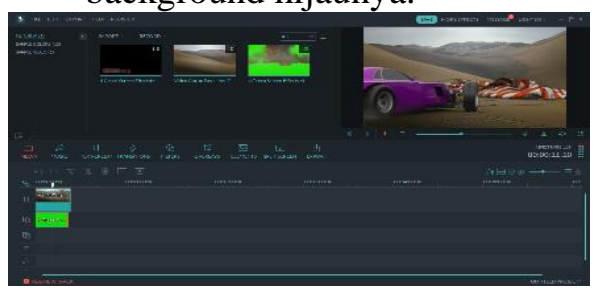

Gambar 11 Video Setelah Background Diganti

12. Apabila proses editing telah selesai langkah selanjutnya adalah mengekspor video kedalam bentuk format yang diinginkan agar nantinya bisa diputar keperangkat media.

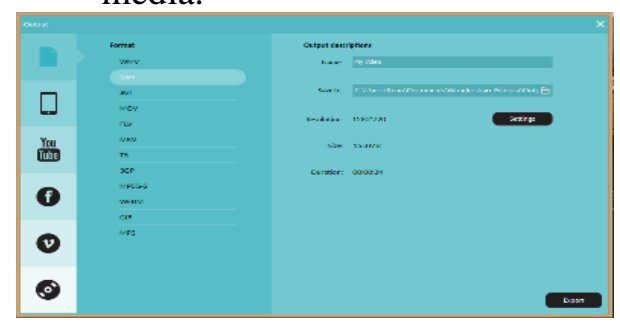

Gambar 12. Output

13. Selain menentukan format video yang diinginkan pada form ini kita juga bisa melakukukan perubah terhadap resolusi yang kita inginkan pada video yang kita miliki.

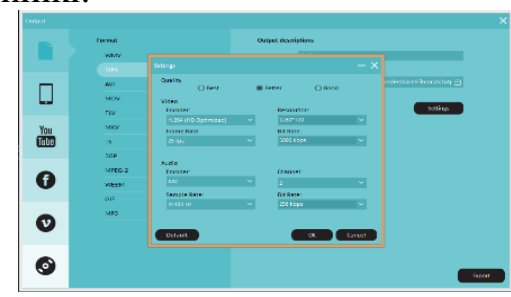

Gambar 13. Menentukan Resolusi dan Qualitas Output Video
14. Selanjutnya proses rendering akan berlangsung beberapa menit tergantung dari panjang pendeknya video yang diedit

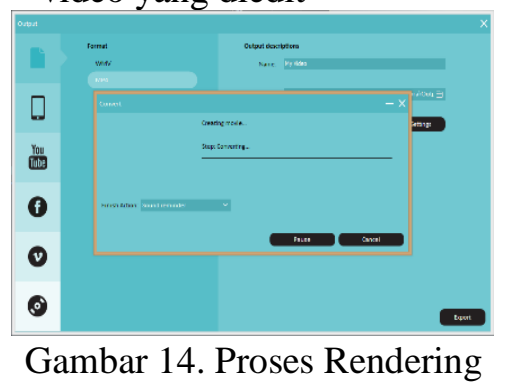

15. Apabila proses rendering telah selesai maka kita tinggal membuka videonya dengan cara masuk ke folder tempat video berada.

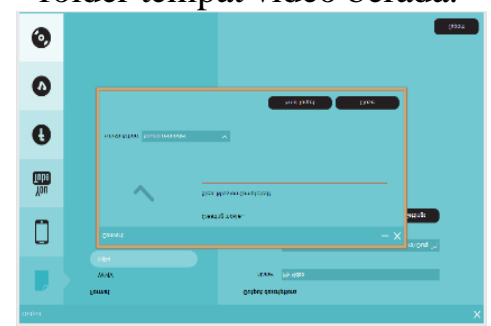

Gambar 15. Proses Rendering Selesai

\section{Dokumentasi Kegiatan}

Berikut foto-foto dokumentasi
acara kegiatan pengabdian kepada
masyarakat di MAS Cipta Simpang Dolok:

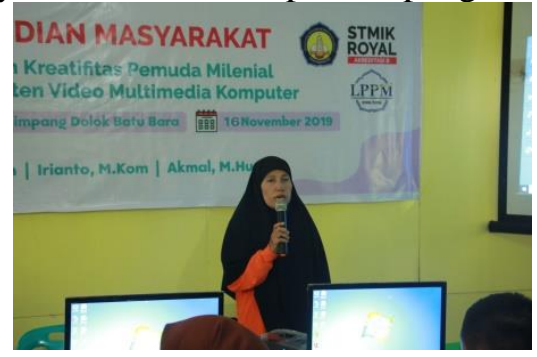

Gambar 16. Pembukaan Acara

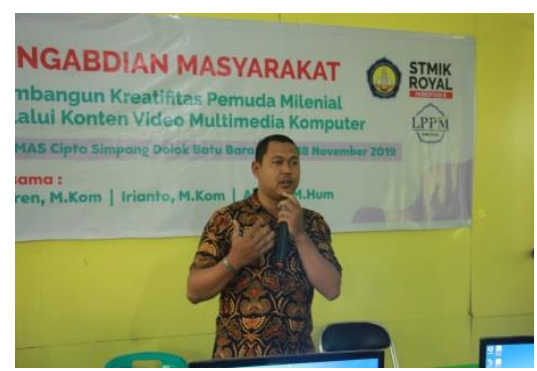

Gambar 17. Penyampaian Materi 
Available online at https://jurnal.stmikroyal.ac.id/index.php/jurdimas
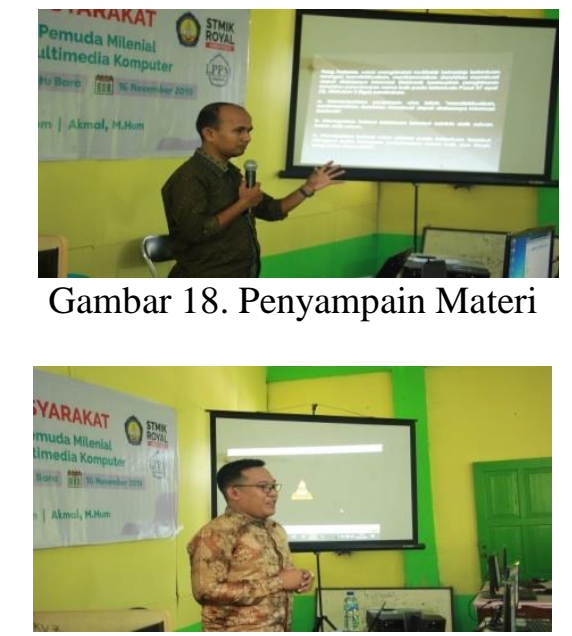

Gambar 19. Penyampain Materi Praktik Editing Video

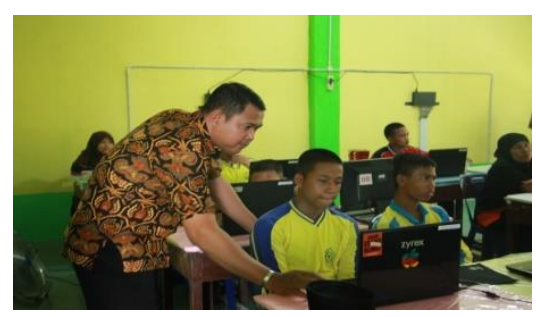

Gambar 20. Memandu Siswa Saat Praktik Editing Video

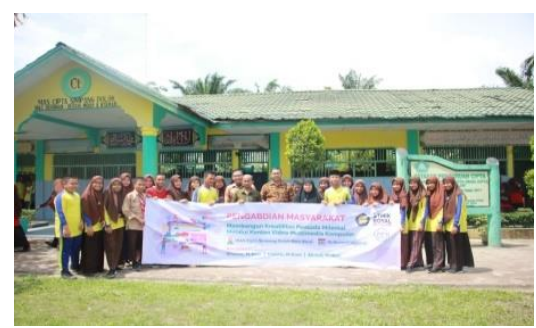

Gambar 21. Foto Bersama Kegiatan PKM Di MAS Simpang Dolok

\section{SIMPULAN}

Kesimpulan dari kegiatan pengabdian kepada masyarakat di MAS Cipta Simpang Dolok ini siswa dan siswi dapat Mengenal mengenai teknologi multimedia menjadi modal dasar bagi siswa untuk mengembangkan kreatifitas melalui konten video dan sebagai penegetahuan tambahan dalam bidang IPTEK secara khusus.
Dengan adanya proses belajar cara editing video dapat membantu siswa didalam menerapkan teknologi multimedia dalam berbagai bidang dan kebutuhan sesuai dengan karakter dan kreatifitas masing-masing.

tidak semua peserta didik mempunyai pemikiran yang tanggap dan mempunyai kemauan untuk memahami proses editing dan mengenali komponen dalam multimedia komputer

\section{UCAPAN TERIMA KASIH}

Dengan ini kami dari kelompok pengadian berterimakasih kepada pihak Sekolah MAS Cipta Simpang Dolok yang telah memberi kesempatan kepada kami dalam mengembangkan pengetahuan, serta kepada LPPM STMIK Royal Kisaran yang telah memfasilitasi kami. Dan kepada Ketua STMIK Royal Kisaran telah mendukung kami dalam melaksanakan pengabdian kepada masyarakat

\section{DAFTRA PUSTAKA}

Bina Nusantara. "Digital Multimedia", 2015. Jakarta, Yulyana Arifin, Michael Yosep Ricky dan Violita Yesmaya

Alfabeta CV. "Multimedia Konsep \& Aplikasi Dalam Pendidikan"2012. Bandung, Munir

Udi firmasyah, a., lubis, a. P., agus, r. T. A., \& nofitri, r. (2018). Pembuatan materi bahan ajar menggunakan animasi flash berbasis multimedia untuk guru smk karya utama tanjungbalai. Jurdimas, l(1), 19-22. 